\title{
ANALISIS PERAN SERTA MASYARAKAT DALAM PENERAPAN KEARIFAN LOKAL PADA PENGELOLAAN HUTAN DI DISTRIK KAYO KABUPATEN YAHUKIMO PAPUA
}

\author{
Nahason Siep, Laak Paskalis, Warsiyah
}

\section{INTISARI}

Tujuan penelitian ini adalah 1). Untuk mengetahui peran serta masyarakat dalam perlindungan hutan. 2). Untuk mengetahui peran serta masyarakat dalam pelestarian lingkungan hidup.

Penelitian ini menggunakan metode random sampling (secara acak) dari populasi responden. Jumlah populasi yang diambil yaitu 2 (dua) Desa yaitu Desa Uwase dan Walet dengan jumlah penduduk dari dua Desa tersebut adalah $47 \mathrm{KK}$. Perolehan data melalui kuesioner, perhitungan menggunakan tabulasi silang dan analisis deskriptif.

Peneliti menemukan Peran serta masyarakat di Desa Uwase dan Walet berpengaruh pada karakteristik pendidikan, sosial ekonomi, budaya dan hukum dalam perlindungan hutan. Persentase masyarakat Desa Uwase dan Walet sangat berperan aktif dalam perlindungan hutan untuk memenuhi kebutuhan ekonomi dan sosial mereka $31 \mathrm{KK}(66 \%)$, budaya $28 \mathrm{KK}(68 \%)$, dan hukum $25 \mathrm{KK}(53 \%)$. Sedangkan peran serta masyarakat di Desa Uwase dan Walet tidak berpengaruh pada jenis kelamin 29 KK (62\%), lama menetap 44 KK (94\%), pekerjaan 2 KK (45\%), pendidikan $15 \mathrm{KK}(32 \%)$, dan pendapatan $15 \mathrm{KK}(32 \%)$.

Kata kunci: Peran serta, Masyarakat, Kearifan Lokal, Pengelolaan Hutan

\section{COMMUNITY ROLE IN THE APPLICATION OF LOCAL WISDOM IN FOREST MANAGEMENT IN DISTRIC KAYO, YAHUKIMO, PAPUA}

\begin{abstract}
The background of this research is to extent the forest in Uwase and Walet villages of Kayo district, which is used by community for their needs in society and economic. The objectives of this research are 1). to find out the community in protecting the forest. 2). to find the community in environment of conservation.

The research uses random sampling method in collecting the data. The amounts of the population are $47 \mathrm{KK}$ from 2 villages. The researcher gives the questioners as the way to collect the data. The research uses cross tabulation calculation.

The result of the research shows that the community in Uwase and Walet villages is influenced by the characteristics of education, society and economic, culture, and law in protecting the forest. The percentages of community role in protecting forest for their needs in Uwase and Walet village is society and economic $31 \mathrm{KK}(66 \%)$, culture $28 \mathrm{KK}(68 \%)$, and law $25 \mathrm{KK}(53 \%)$ while the community role in Uwase and Walet villages is not influenced by the characteristics of gender 29
\end{abstract}


$K K(62 \%)$, length of stay $44 K K(94 \%)$, employment 2 KK (45\%), education 15 KK (32\%), and income $15 \mathrm{KK}(32 \%)$. Based on the result of this research, the researcher hopes this research can give contributions to the readers who learn about community role in the application of local wisdom in forest management

Keywords: the community role, local wisdom, forest management 


\section{PENDAHULUAN}

\subsection{Latar Belakang}

Pelaksanaan peran serta masyarakat dalam perlindungan lingkungan hidup adalah kesatuan ruang dengan semua benda, daya, makhluk-makhluk hidup lainnya termasuk manusia, perilakunya yang dipengaruhi oleh strategis perlindungan sumber daya alam itu dan perlindungan lingkungan hidup agar supaya dapat berkesinambungan demi untuk generasi sekarang dan generasi masa depan.

Peran serta masyarakat dalam perlindungan lingkungan hidup adalah suatu upaya berencana untuk memanfaatkan serta perlindungan bagi kepentingan masyarakat mengingat, bahwa pertumbuhan masyarakat yang terus meningkat sampai saat ini sehingga setiap orang membutuhkan perlindungan daya di dalam lingkungan hidupnya.

\subsection{Rumusan Masalah}

Berdasarkan latar belakang masalah di atas maka timbul rumusan masalah yaitu bagaimanakah pelaksanaan peran serta masyarakat dalam pelaksanaan hukum perlindungan lingkungan hidup di Distrik Kayo?

\subsection{Batasan Masalah}

Agar penelitian ini tidak terlalu melebar dan dapat berjalan secara terarah mencapai tujuan, maka diberikan batasan sebagai berikut:

a. Peran serta masyarakat dalam hukum perlindungan hutan.

b. Peran serta masyarakat dalam pelestarian lingkungan hidup.

1.4 Tujuan Penelitian

Adapun tujuan penelitian dapat dijelaskan sebagai berikut:

a. Untuk mengetahui peran serta masyarakat dalam hukum perlindungan hutan.

b. Untuk mengetahui peran serta masyarakat dalam pelestarian lingkungan hidup.

1.5 Manfaat Penelitian

Manfaat yang dapat di ambil dari penelitian ini adalah sebagai berikut:

a. Menambah wawasan, pengetahuan dan pengalaman bagi peneliti mengenai analisis peran serta masyarat dalam perlindungan lingkungan hidup di Distrik Kayo.

b. Memberikan manfaat bagi masyarakat lingkungan hidup.

c. Memberikan pengembangan ilmu pengetahuan untuk penelitian selanjutnya.

\section{TINJAUAN PUSTAKA}

2.1 Peran Serta Masyarakat. 
Berdasarkan undang-undang Nomor 32 Tahun 2009, mengenai lingkungan hidup terhadap masyarakat tidak dapat dilakukan sendiri melainkan harus selalu bersama-sama pemerintah dan melibatkan swadaya masyarakat banyak. Peran serta masyarakat amat penting untuk meningkatkan daya guna dan hasil guna sistem pengelolaan sumber daya alam dan lingkungan hidup. Mutu peran serta masyarakat tergantung kepada wawasan lingkungan tingkat kesadaran, kekuatan dan profesi masyarakat serta kesempatan dan ruang gerak yang memandai bagi masyarakat karena masyarakatlah yang menjadi tolak ukur pembangunan.

2.2 Peran Serta Masyarakat dalam Pelaksanaan Hukum Perlindungan.

Waluyo (2002), mengatakan bahwa peran serta masyarakat pada dasarnya adalah suatu proses yang melibatkan masyarakat umumnya dikenal sebagai peran serta masyarakat, yaitu proses komunikasi dua arah yang berlangsung terus-menerus untuk meningkatkan pengertian masyarakat secara penuh atas suatu proses kegiatan, di mana masalah-masalah dan kebutuhan lingkungan sedang dianalisis. Menurut Leden Marpaung (1997), banyak yang memandang peran serta masyarakat sematamata sebagai penyampaian informasi (public informasi), penyuluhan, bahkan sekedar alat public relation agar kegiatan tersebut dapat berjalan tanpa hambatan karenanya peran serta masyarakat tidak saja digunakan sebagai saran untuk mencapai tujuan, tetapi juga digunakan sebagi tujuan.

2.3 Hukum Perlindungan Lingkungan Hidup

Hukum Perlindungan adalah suatu perlindungan yang diberikan terhadap subjek hukum dalam bentuk perangkat hukum baik yang bersifat preventif maupun yang bersifat represif, baik yang tertulis maupun tidak tertulis. Dengan kata lain hukum perlindungan sebagai suatu gambaran dari fungsi hukum,yaitu konsep dimana hukum dapat memberikan suatu keadilan, ketertiban, kepastian, kemanfaatan dan kedamaian (http//

www.artikata.com/artiperlindung anhukum.html) 
2.4 Kerangka Berpikir

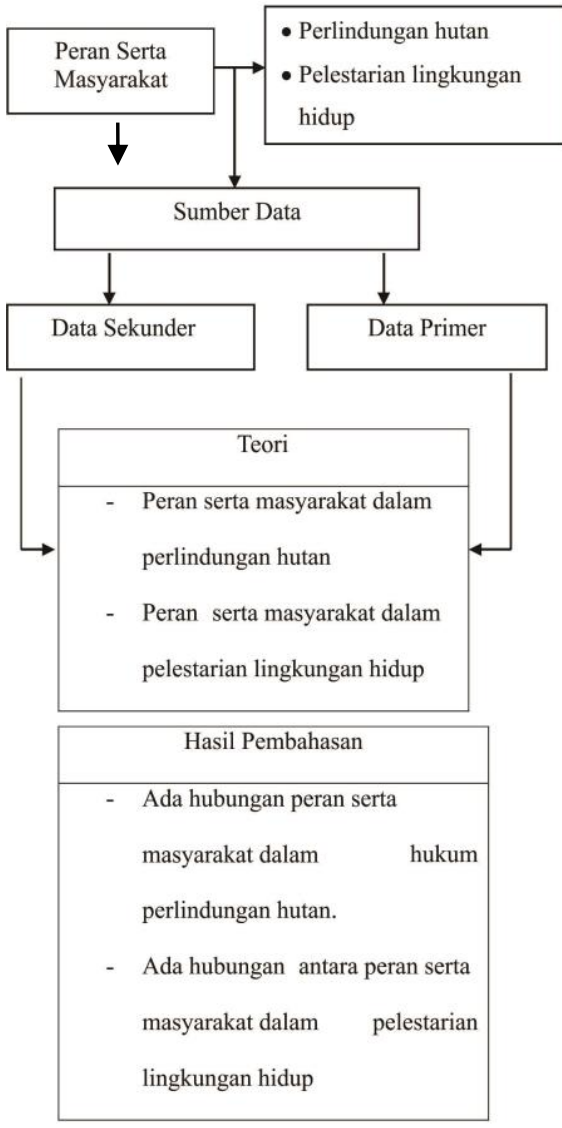

Gambar 1. Kerangka berpikir

\subsection{Hipotesa}

a. Ada hubungan peran serta masyarakat dan hukum perlindungan hutan.

b. Ada hubungan peran serta masyarakat dan pelestarian lingkungan hidup.

\section{METODE PENELITIAN}

3.1 Lokasi Penelitian

Penelitian dilaksanakan di Desa Uwase dan Walet Distrik Kayo kabupaten Yahukimo.

\subsection{Objek Penelitian}

Penelitian ini yang menjadi objek atau fokus penelitian adalah peran serta masyakat dalam pelaksanaan hukum perlindungan lingkungan hidup.

3.3 Waktu Penelitian

Waktu penelitian ini dilakukan pada bulan September - Desember tahun 2018 di Desa Uwase dan Walet di Distrik Kayo Kabupaten Yahukimo.

\subsection{Variabel Penelitian}

- Variabel bebas:

Peran serta masyarakat.

- Variabel terikat:

Hukum perlindungan dan pelestarian lingkungan hidup.

\subsection{Jenis Data}

Dua jenis data yang di perlukan dalam penelitian ini, yaitu data sekunder dan data primer. Data primer maupun sekunder dijabarkan dari variabel utama setiap jenis data digunakan secara rinci beserta sumber datanya

3.6 Pengumpulan Data

Pengamatan dan pengumpulan data primer langsung dilakukan di lapangan pada sampel responden menggunakan metode random sampling atau melakukan pengambilan sampel di masyarakat secara acak. Pelaksanaanya dengan cara menguji responden di tempat tinggalnya dan melakukan 
wawancara, wawacara di dasarkan atas daftar pertanyaan (questioner). Pengumpulan data sekunder menggunakan cara mendatangi kantor-kantor dan dinas-dinas terkait.

\subsection{Analisis Data}

Analisis crosstabulation adalah suatu metode analsis berbentuk tabel, dimana menampilkan tabulasi silang atau tabel kontingensi yang digunakan untuk mengidentifikasi dan mengetahui apakah ada korelasi atau hubungan antara satu variabel dengan variabel yang lain. Singkatnya, analisis crosstabulation merupakan metode untuk mentabulasikan beberapa variabel yang berbeda ke dalam suatu matriks. Tabel yang dianalsis ini adalah hubungan antara variabel dalam baris dengan variabel dalam kolom.

\section{HASIL PENELITIAN DAN PEMBAHASAN}

4.1 Kondisi Lokasi di Daerah Penelitian

1. Lokasi Penelitian ini di Desa Uwase dan Walet Kecamatan Kayo Kabupaten Yahukimo, Provinsi Papua. Hutan di kedua distrik merupakan dua hutan yaitu, hutan larang (adat) dan hutan biasa. Adapun lokasi penelitian dapat ditempuh dengan mengunakan transportasi udara (Pesawat) dengan jangka waktu lebih 25 menit dari Kabupaten Yahukimo.

2. KabupatemYahukimo memiliki luas wilayah $17.152 \mathrm{~km}^{2}$ dengan jumlah penduduk jiwa, terbagi dari jumlah laki-laki 86.735 jiwa dan perempuan 77.777 jiwa yang terdiri dari 51 distrik dan 517 kampung I kelurahan. Distrik Kayo terdiri dari 7 kampung dengan luas wilayah $198 \mathrm{~km}^{2}$.

a. Kampung Walet Jumlah penduduk kampung walet yaitu 180 jiwa dengan jumlah kepala keluarga (KK) 23 KK, terbagi dalam laki-laki 100 Jiwa dan perempuan 80 Jiwa.

b. Kampung Uase Jumlah penduduk kampung Uwase yaitu 200 jiwa dengan jumlah kepala keluarga (KK) $24 \mathrm{KK}$, terbagi dalam laki-laki 120 Jiwa dan perempuan 80 Jiwa.

3. Iklim yang terdapat di daerah penelitian berupa iklim tropis dengan cuaca panas sebagai ciri khasnya. Tipe iklim di daerah penelitian didasarkan pada klarifikasi tipe iklim menurut Schmidt-Ferguson yang mendasarkan pada curah hujan bulanan atau bulan basah dan bulan kering dalam satu tahun, jumlah bulan basah 6 , dengan curah hujan di bulan basah adalah $200 \mathrm{~mm} / \mathrm{bulan}$ dan 
jumlah curah hujan di musim kering adalah $60 \mathrm{~mm} /$ bulan jadi dapat diketahui daerah penelitian mempunyai tipe iklim $\mathrm{E}$ atau tipe iklim agak kering. Suhu rata-rata di Desa Uwase dan Walet sekitar $30^{\circ} \mathrm{C}$. Desa Uwase dan Walet hanya memiliki dua musim yaitu musim penghujan dan musim kemarau.

\subsection{Karakter Responden}

1. Jenis Kelamin

Berdasarkan sampel yang diambil jumlah jenis laki-laki terbesar adalah $24 \mathrm{KK}$ (62\%), karena pada umumnya pengisian kuesioner dilakukan oleh kepala keluarga yang umumnya lakilaki.

Tabel 4.1 Distribusi Responden Menurut Jenis Kelamin

\begin{tabular}{cccc}
\hline No & $\begin{array}{c}\text { Jenis } \\
\text { Kelamin }\end{array}$ & Jumlah & $\begin{array}{c}\text { Percentase } \\
(\%)\end{array}$ \\
\hline 1. Laki-Laki & 29 & $62 \%$ \\
\hline 2. Perempuan & 18 & $38 \%$ \\
\hline Jumlah & $\mathbf{4 7}$ & $\mathbf{1 0 0}$ \\
\hline
\end{tabular}

Tabel 4.1 menunjukan bahwa distribusi responden yang berjenis kelamin laki-laki berjumlah 29 KK (62\%) dan responden yang berjenis kelamin perempuan sebanyak $18 \mathrm{KK}$ (38\%).

2. lama Menetap
Sistem hak milik hutan bertentangan dengan kesinambungan ekosistem hutan, serta dengan masa depan bagi pengelolaan kawasan hutan secara berkelanjutan.

Tabel 4.2 Dristribusi Responden

Berdasarkan Lama Menetap

\begin{tabular}{cccc}
\hline NO & $\begin{array}{c}\text { Lama } \\
\text { Menetap }\end{array}$ & Jumlah & $\begin{array}{c}\text { Persentase } \\
\text { (\%) }\end{array}$ \\
1. & $1 \mathrm{~s} / \mathrm{d} 5$ & 3 & $6 \%$ \\
& Tahun & & \\
2. & $=5$ Tahun & 44 & $94 \%$ \\
& Jumlah & $\mathbf{4 7}$ & $\mathbf{1 0 0}$ \\
\hline
\end{tabular}

Tabel 4.2 menunjukkan distribusi responden yang menetap lebih dari 5 tahun berjumlah 44 KK (94\%) lebih besar dari pada responden yang menetap $1 \mathrm{~s} / \mathrm{d} 5$ tahun berjumlah 3 KK (6\%). Dengan kata lain penduduk asli lebih banyak dibandingkan dengan masyarakat pendatang.

3. Pendidikan

Peran serta masyarakat dan bentuk peranserta sangat dipengaruhi oleh tingkat pendidikan masyarakat itu sendiri. 
Tabel 4.3 Distribusi Responden Berdasarkan Pendidikan

\begin{tabular}{cccc}
\hline NO & $\begin{array}{c}\text { Lama } \\
\text { Menetap }\end{array}$ & Jumlah & $\begin{array}{c}\text { Persentase } \\
(\%)\end{array}$ \\
1. & Tidak & 7 & $15 \%$ \\
2. & Sekolah & & \\
3. & Masar & 12 & $26 \%$ \\
4. & Tinggi & 15 & $28 \%$ \\
& & $\mathbf{4 7 h}$ & $\mathbf{1 0 0}$ \\
& & &
\end{tabular}

Tabel 4.3 menunjukkan distribusi responden yang berpendidikan tinggi berjumlah 15 KK (32\%) lebih besar dari pada responden yang berpendidikan menengah $13 \mathrm{KK}$ (28\%) dan responden yang berpendidikan dasar $12 \mathrm{KK}$ $(26 \%)$ dan sangat sedikit responden yang tida bependidikan 7 KK (15\%).

4. Pekerjaan

Mata pencaharian merupakan salah satu faktor yang berpengaruh dalam Peran serta masyarakat dalam penerapan kearifan lokal pada pengelolaan hutan.

Tabel 4.4 Distribusi Responden Berdasarkan Pekerjaan

\begin{tabular}{cccc}
\hline NO & Pekerjaan & Jumlah & $\begin{array}{c}\text { Percentase } \\
(\%)\end{array}$ \\
\hline 1. & Petani & 19 & $40 \%$ \\
\hline 2. & PNS/TNI/P & 21 & $45 \%$ \\
& OLRI & & \\
\hline 3. & Wiraswasta & 7 & $15 \%$ \\
& Pedagang & & \\
\hline & Jumlah & $\mathbf{4 7}$ & $\mathbf{1 0 0}$ \\
\hline
\end{tabular}

Tabel 4.4 menunjukkan distribusi responden yang PNS/TNI/POLRI 21 KK (45\%) lebih besar berjumlah dari pada responden yang mempunyai pekerjaan petani 19 KK (40\%) dan responden yang mempunyai pekerjaan wiraswasta/pedagang 7 KK (15\%).

\section{Pendapatan}

Pendapatan masyarakat yang bermukim di sekitar hutan biasanya akan memengaruhi pengetahuan dan kesadaran tentang kelestarian hutan sebagai suatu bagian dari ekosistem pemukiman tersebut, sehingga berpengaruh terhadap peran serta masyarakat dalam mengelola hutan di daerah tersebut.

Tabel 4.5 Distribusi Responden Berdasarkan Tingkat Pendapatan

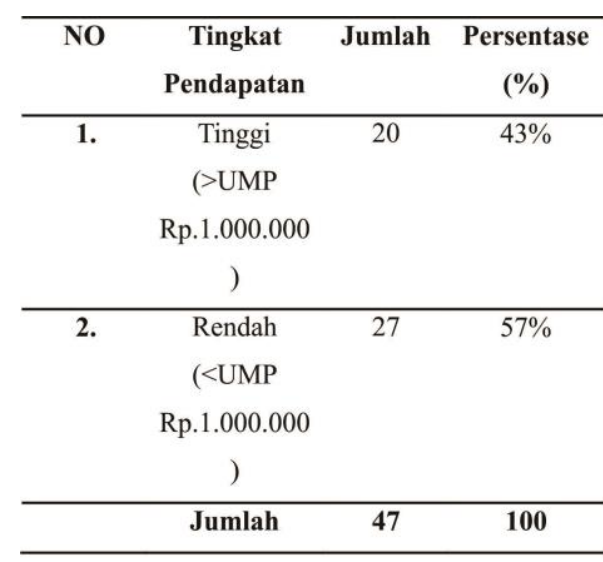

\begin{tabular}{lrr}
\multicolumn{1}{c}{ Tabel } & 4.5 & tingkat \\
pendapatan & \multicolumn{2}{c}{ menunjukkan } \\
distribusi & responden & yang \\
berpendapatan & rendah & lebih
\end{tabular}


besar yaitu sebesar 27 (57\%)

dari pada responden yang berpendapatan tinggi yaitu sebesar 20 (43\%).

6. Sosial-Ekonomi

Sistem pengelolaan sumberdaya hutan pada kawasan hutan larang (wesama) atau hutan biasa, yang memberi kesempatan kepada masyarakat setempat sebagai pelaku atau mitra utama dalam rangka meningkatkan kesejahteraannya dan mewujudkan kelestarian hutan.

Tabel 4.6 Distribusi Dukungan Responden Terhadap Pengelolaan Hutan Berkelanjutan Berdasarkan Sosial-Ekonomi.

\begin{tabular}{|c|c|c|c|}
\hline No & Sosial-Ekonomi & Jumlah & $\begin{array}{l}\text { Persent } \\
\text { ase }(\%)\end{array}$ \\
\hline \multicolumn{2}{|c|}{$\begin{array}{l}\text { 1. Mendukung } \\
\text { (Hutan } \\
\text { digunakan untuk } \\
\text { kebutuhan } \\
\text { ekonomi \& } \\
\text { sosial seperti } \\
\text { membuat kebun, } \\
\text { tali rotan untuk } \\
\text { buat gelang } \\
\text { tangan, } \\
\text { Jembatan, dan } \\
\text { lain-lain) }\end{array}$} & 31 & $66 \%$ \\
\hline \multicolumn{2}{|c|}{\begin{tabular}{l} 
2. Tidak \\
\multicolumn{1}{c}{ Mendukung } \\
(Tidak semua \\
hutan bisa \\
digunakan untuk \\
kebutuan \\
ekonomi \& \\
sosial seperti \\
membuat kebun, \\
tali rotan untuk \\
buat gelang \\
tangan, dan \\
Jembatan, dan \\
lain-lain) \\
\end{tabular}} & 16 & $34 \%$ \\
\hline & Jumlah & 47 & 100 \\
\hline
\end{tabular}

Tabel 4.6 menunjukkan bahwa distribusi responden yang sosial ekonominya tidak mendukung peran serta dalam penerapan kearifan lokal pada pengelolaan hutan yaitu sebesar 16 KK (34\%), sedangkan pada sosial ekonomi yang mendukung peran serta dalam penerapan kearifan local pada pengelolaan hutan yaitu berjumlah $31 \mathrm{KK}$ (66\%).

7. Budaya

Di Indonesia masih memiliki kearifan lokal (adat) dalam pengelolaan sumber daya alam. Sistem-sistem lokal ini berbeda satu sama lain yang berkembang dan berubah secara evolusioner sesuai kondisi sosial budaya dan tipe ekosistem setempat.

Tabel 4.7 Distribusi Dukungan

Reponden Berdasarkan

Budaya Masyarakat

\begin{tabular}{|c|c|c|c|}
\hline & Budaya & Jumlah & $\begin{array}{c}\text { Persentase } \\
(\%)\end{array}$ \\
\hline & $\begin{array}{l}\text { Mendukung } \\
\text { (Hutan di } \\
\text { gunakan untuk } \\
\text { membuat Pagar, } \\
\text { rumah adat } \\
\text { untuk } \\
\text { perempuan dan } \\
\text { rumah adat laki- } \\
\text { laki (Honai), } \\
\text { dan lain-lain) }\end{array}$ & 28 & $60 \%$ \\
\hline & $\begin{array}{l}\text { Tidak } \\
\text { Mendukung } \\
\text { (Tidak semua } \\
\text { hutan bisa di } \\
\text { gunakan untuk } \\
\text { membuat Pagar, } \\
\text { rumah adat } \\
\text { untuk } \\
\text { perempuan dan } \\
\text { rumah adat laki- } \\
\text { laki (Honai), } \\
\text { dan lain-lain) }\end{array}$ & 19 & $40 \%$ \\
\hline & Jumlah & 47 & 100 \\
\hline
\end{tabular}


Tabel 4.7 menunjukkan distribusi responden yang menjawab kuesioner budaya yang mendukung peran serta dalam penerapan kearifan lokal pada pengelolaan hutan yaitu sebesar 28 KK (60\%) lebih besar dari pada budaya yang tidak mendukung peran serta dalam penerapan kearifan local pada pengelolaan hutan yaitu sebesar 19 KK (40\%).

8. Penegakan Hukum Bidang Pelestarian Kearifan Lokal pada Pengelolahan Hutan

Pelestarian hutan serta fungsinya secara berkesinambungan perlu ada suatu aturan dalam pengambilan keputusan, bersifat konsultatif dan kemitraan antara pemerintah sebagai pengambil keputusan dengan masyarakat yang berkepentingan.

Table 4.8 Distribusi Dukungan

Responden terhadap

Penegakan Hukum

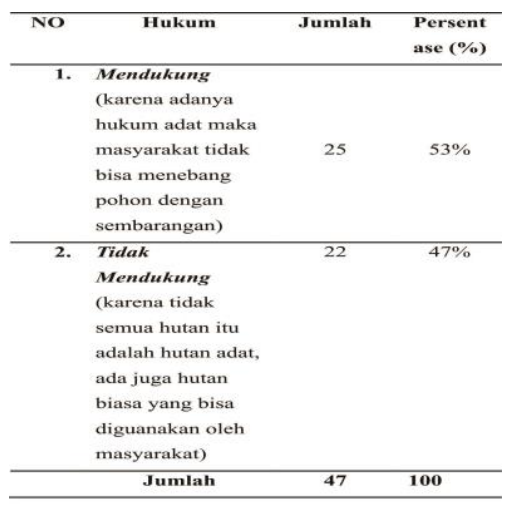

Tabel 4.9 menunjukkan distribusi responden yang memberikan jawaban hukum yang mendukung peran serta dalam pelestarian kearifan lokal pada pengelolaan hutan sebesar 25 KK (53\%) lebih besar dari pada hukum yang tidak mendukung peran serta dalam pelestarian kearifan lokal pada pengelolaan hutan yaitu sebesar $22 \mathrm{KK}(47 \%)$.

Tabel 4.9 Tabulasi Silang

\begin{tabular}{|l|c|c|c|}
\hline \multirow{2}{*}{$\begin{array}{l}\text { Variabel } \\
\text { Bebas }\end{array}$} & \multicolumn{2}{|c|}{ Peran Serta Masyarakat } & $\begin{array}{c}\text { Total } \\
(\%)\end{array}$ \\
\cline { 2 - 3 } & $\begin{array}{c}\text { Tidak } \\
\text { Vendukung } \\
\text { Veriabel } \\
\text { Terikat }\end{array}$ & $\begin{array}{c}\text { Mendukung } \\
(\%)\end{array}$ & \\
\hline Sosial & $16 \mathrm{KK}$ & $31 \mathrm{KK}$ & $100 \%$ \\
Ekonomi & $(34 \%)$ & $(66 \%)$ & \\
\hline Budaya & $19 \mathrm{KK}(40$ & $28 \mathrm{KK}(60$ & $100 \%$ \\
& $\%)$ & $\%)$ & \\
\hline Hukum & $22 \mathrm{KK}$ & $25 \mathrm{KK}$ & $100 \%$ \\
& $(47 \%)$ & $(53 \%)$ & \\
\hline
\end{tabular}

Berdasarkan tabel 4.9 diatas dapat disimpulkan bahwa masyarakat Desa Uwase dan Walet sudah sangat berperan aktif dalam penerapan kearifan lokal pada pengelolaan hutan hal ini ditunjukan dalam persentase mendukung diatas yakni dalam bidang sosial ekonomi $31 \mathrm{KK}$ (66\%), budaya $28 \mathrm{KK}(60 \%)$, 25 KK (53\%). Dengan demikian dapat disimpulkan bahwa masyarakat Desa Uwase dan Walet sangat berperan aktif dalam pelestarian kearifan lokal 


\section{PEMBAHASAN}

1. Jenis Kelamin

Hubungan jenis kelamin dengan peran serta masyarakat dalam penerapan kearifan lokal pada pengelolaan hutan adalah dalam hal pengetahuan, aktivitas, pekerjaan, peran serta dan mengikuti pertemuan-pertemuan. pada uji chi-square jenis kelamin tidak terdapat hubungan yang signifikan dengan peran serta masyarakat terhadap kearifan lokal pada pengelolaan hutan. Hal ini mungkin dipengaruhi oleh faktor lain yang tidak diteliti. Asep (2002) menyebutkan bahwa perkerjaan, pengetahuan, peran serta, pertemuan-pertemuan dan aktivitas di mana umumnya peran serta laki-laki berbeda dengan kaum perempuan.

2. Lama Menetap

Hubungan lama menetap dengan peran serta masyarakat dalam penerapan kearifan lokal pada pengelolaan hutan adalah jangka waktu tinggal menetap masyarakat setempat di sekitar wilayah hutan yang menggunakan sumber daya hutan sebagai hak-hak dan kewajibannya untuk kebutuhan hidupnya pada kelangsungan ekosistem hutan tersebut.

3. Pendidikan

Hubungan pendidikan dengan peran serta masyarakat dalam penerapan kearifan lokal pada pengelolaan hutan adalah semakin tinggi tingkat pendidikan responden akan memberikan tingkat peran serta yang tinggi pula. Hal ini sejalan dengan pendapat (Soekanto, 1985) yang menjelaskan bahwa pencapaian taraf pendidikan tertentu akan mempunyai potensi yang yang lebih baik untuk penyesuaian diri tentang sikap dan pendapat, dibandingkan dengan mereka yang berpendidikan rendah.

4. Pekerjaan

Variabel pekerjaan menunjukkan peran serta kurang baik pada tiap jenis pekerjaan yaitu: petani 40\%, Wiraswasta/pedagang $15 \%$, dan PNS/TNI/POLRI $45 \%$ di Desa Uwase dan Walet. Hubungan pekerjaan dengan peran serta masyarakat dalam penerapan kearifan lokal pada pengelolaan hutan adalah mata pencaharian masyarakat setempat yang berada di sekitar hutan secara musiman atau dominan sehingga motivasi dan aktivitas peranserta masyarakat tersebut bisa terlaksana (Damar, 2008).

5. Pendapatan

Hubungan pendapatan dengan peran serta masyarakat dalam penerapan kearifan lokal pada pengelolaan hutan adalah meningkatnya pendapatan masyarakat maka peran serta masyarakat semakin baik disebabkan oleh pendapatan yang 
cukup maka pendidikan, pengetahuan tentang peran serta dalam penerapan kearifan lokal pada pengelolaan hutan pengelolaan hutan di lingkungannya sendiri semakin meningkat pula.

6. Social- Ekonomi

Variabel sosial ekonomi, maka responden yang memiliki sosial ekonomi mendukung lebih banyak yang memiliki peran serta baik yaitu 31 KK (66\%), dan pada sosial ekonomi tidak mendukung memiliki peran serta kurang baik yaitu $16 \mathrm{KK}$ orang (34\%). Hal ini sesuai yang disebutkan (Hubeis, 1990) bahwa bentuk peran serta masyarakat akan sangat dipengaruhi oleh latar belakang mereka, mencakup karakteristik sosial dan ekonomi.

7. Budaya

Budaya masyarakat, yang tidak mendukung lebih banyak memiliki peran serta kurang baik sebanyak 19 orang $(60 \%)$ dan budaya masyarakat yang mendukung peran serta baik sebanyak 28 orang (40\%). Hubungan budaya dengan peran serta masyarakat dalam penerapan kearifan lokal pada pengelolaan hutan adalah penduduk yang hidup dalam satuan-satuan komunitas berdasarkan asal-usul leluhur secara turun-temurun di atas suatu wilayah adat, yang memiliki kedaulatan atas tanah dan kekayaan alam, kehidupan sosial budaya yang diatur oleh hukum adat, dan lembaga adat yang mengelola keberlangsungan kehidupan masyarakatnya (KMAN dalam Nababan, 2002).

8. Hukum

Pada variabel hukum, terdapat peran serta mendukung yaitu 25 orang (53\%), dan yang tidak mendukung hukum 22 orang (47\%).Hubungan Hukum dengan peran serta masyarakat dalam penerapan kearifan lokal pada pengelolaan hutan adalah untuk menjalankan fungsi hutan keseluruhan perlu adanya suatu aturan dan undang-undang yang mengatur tatanan fungsi hutan.

\section{KESIMPULAN DAN SARAN}

1. Peran serta masyarakat di Desa Uwase dan Walet berpengaruh pada karakteristik, sosial ekonomi, budaya dan hukum dalam perlindungan hutan. Persentase masyarakat Desa Uwase dan Walet sangat berperan aktif dalam perlindungan hutan untuk memenuhi kebutuhan ekonomi dan sosial mereka $31 \mathrm{KK}(66 \%)$, budaya $28 \mathrm{KK}$ (60\%), dan hukum $25 \mathrm{KK}$ $(53 \%)$.

2. Peran serta masyarakat di Desa Uwase dan Walet dalam pelestarian lingkungan tidak berpengaruh dari jenis 
kelamin $29 \mathrm{KK}(62 \%)$, lama menetap 44 KK (94\%), pekerjaan $21 \mathrm{KK}$ (45\%), dan pendidikan 15 (KK 32\%).

\section{Saran}

1. Perlu dilakukan penyuluhan melalui media yang tepat tentang pentingnya penerapan kearifan lokal kepada masyarakat setempat, serta juga perlu dilakukan penyuluhan tentang hukum dan aturan tentang perlindungan hutan di Distrik Kayo.

2. Diharapkan Pemerintah Daerah Kabupaten Yahukimo lebih mengupayakan peningkatan ekonomi rumah tangga masyarakat yang bermukim di sekitar hutan yang ada di Distrik Kayo.

\section{Daftar Pustaka}

Asep. S, 2002, Perubahan Sikap, Prilaku Masyarakat Pesisir Berbasis Masyarakat http//www.manado.wasanta ra.net.id (diakses 15 Agustus 2008).

Damar, Partisipasi Masyarakat dalam Pengelolaan Hutan Desa, http//www.damarnet.org. (diakses 16 Oktober 2008).
Hubeis, 1990, Provincial Forest Economic Profiles, Ministry of Forestry \& FAO, Jakarta Dec 1989; Jakarta Post 3/Dec/03; FWI/GFW The State of the Forest, Indonesia, 2002, MoF website tables at http://mofrinet.cbn.net.id (diakses 15 Agustus 2008).

Marpaung, Leden M. 1997. Tindakan Pidana Lingkungan Hidup dan Masalah Prevensinya. Jakarta: Sinar Grafika

Nababan, 2002, Peran Serta Masyarakat dalam Pengelolaan Lingkungan, http//www.pacific.net.id, acsess 15 Agustus 2008.

Soekanto, S, 1985. Sosiologi Ruang Lingkup dan Aplikasinya, Remaja Karya, Jakarta.

Waluyo. 2002. Pribadi, Peran Serta Masyarakat dan Penyelesaianya berdasarkan Hukum Lingkungan. Salatiga: Satyawacana 